06

\title{
Исследование влияния вторичных объемных концентраторов на выходные параметры фотоэлектрических модулей
}

\author{
() Н.С. Потапович, Н.Ю. Давидюк, В.Р. Ларионов, В.П. Хвостиков \\ Физико-технический институт им. А.Ф. Иофрфе РАН, \\ 194021 Санкт-Петербург, Россия \\ e-mail: nspotapovich@mail.ioffe.ru
}

Поступило в Редакцию 13 марта 2020 г.

В окончательной редакции 15 апреля 2020 г.

Принято к публикации 24 апреля 2020 г.

Разработаны и исследованы вторичные оптические концентраторы (фоконы), предназначенные для работы в солнечном концентраторном фотоэлектрическом модуле с линзами Френеля. Были созданы как объемные преломляющие концентраторы, так и концентраторы с внутренними отражающими поверхностями в форме перевернутых усеченных конусов и пирамид. Использование фоконов в конструкции фотоэлектрического модуля позволило добиться значительного увеличения (больше чем в два раза) допустимого угла отклонения оптической оси концентраторной системы от нормального положения.

Ключевые слова: фотоэлектрический преобразователь, концентраторный фотоэлектрический модуль, вторичный оптический концентратор, фокон, линза Френеля.

DOI: 10.21883/JTF.2020.12.50129.88-20

\section{Введение}

Одним из наиболее перспективных методов получения электроэнергии из возобновляемых источников является прямое преобразование концентрированного солнечного излучения с использованием высокоэффективных полупроводниковых фотоэлектрических преобразователей (ФЭП) каскадного типа и недорогих оптических концентраторных систем. В настоящее время значения КПД ФЭП на основе трехкаскадных гетероструктур GaInP/GaAs/Ge превышают уровень 40\% [1]. Использование оптических концентраторов, обеспечивающих кратность концентрирования солнечного излучения 500-1000, позволяет пропорционально сократить площадь ФЭП, что способствует снижению доли затрат на дорогие полупроводниковые структуры в стоимости единицы установленной мощности солнечной энергоустановки.

В качестве первичной концентрирующей оптики в концентраторных фотоэлектрических модулях (КФЭМ) широко используются линзы Френеля (ЛФ). Одним из недостатков таких линз при фокусировке солнечного излучения является снижение концентрирующей способности (уменьшение средней концентрации при одновременном увеличении размера фокального пятна) и энергетической эффективности, обусловленные наличием хроматических аберраций [2].

Введение в оптическую схему вторичных оптических концентраторов (ВОК) позволяет сгладить негативные эффекты, связанные с хроматическими аберрациями и неравномерным распределением излучения по поверхности фотоэлектрических преобразователей $[3,4]$. Применение ВОК также обеспечивает расширение функ- циональных возможностей концентраторного модуля в части снижения требований по точности ориентации и рост его энергопроизводительности в режимах активного слежения за положением Солнца, а также способствует компенсации погрешностей взаимного расположения элементов конструкции модуля.

Используемое на практике разнообразие элементов вторичной оптики включает как зеркальные, так и преломляющие элементы различной формы, а также их сочетания [5-10]. К зеркальным элементам относятся перевернутые усеченные конусы и перевернутые усеченные пирамиды с внутренними отражающими поверхностями. В качестве преломляющих элементов используются куполообразные сферические линзы, объемные пирамидальные, конические и параболические концентраторы, а также Köhler-интеграторы. Следует отметить, что такие сложные оптические элементы, как параболические концентраторы или Köhler-интеграторы, имеют значительно более высокую стоимость изготовления по сравнению с другими типами ВОК, что ограничивает их широкое практическое применение. Наиболее простыми по конструкции и доступными при изготовлении являются вторичные концентраторы в виде перевернутых усеченных конусов и перевернутых усеченных пирамид.

В настоящей работе были исследованы характеристики концентраторных фотоэлектрических модулей, в фокусирующих оптических системах которых были использованы в качестве вторичных оптических концентраторов элементы преломляющего и отражающего типа в виде перевернутых усеченных конусов и перевернутых усеченных пирамид. 

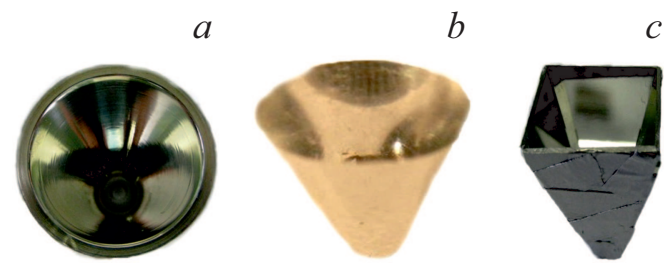

$c$

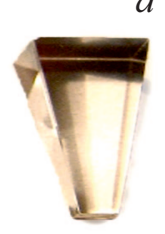

Рис. 1. Внешний вид разработанных вторичных оптических концентраторов: $a, c$ - отражающие фоконы конической и пирамидальной формы; $b, d-$ преломляющие фоконы конической и пирамидальной формы.

\section{1. Конструкции фотоэлектрических модулей с вторичными оптическими концентраторами}

Для проведения исследований были изготовлены одиночные КФЭМ, содержащие в качестве первичного оптического концентратора ЛФ типа „силикон на стекле“ квадратной формы (размер стороны $40 \mathrm{~mm}$, фокусное расстояние $f=70 \mathrm{~mm}$ ) [11]. В фокусе ЛФ располагался трехпереходный $\mathrm{GaInP} / \mathrm{GaAs} / \mathrm{Ge}$ ФЭП с фоточувствительной поверхностью диаметром $1.7 \mathrm{~mm}$. При оптимальных параметрах ЛФ, точной ориентации модуля и отсутствии вторичной оптики средний коэффициент концентрации излучения на ФЭП составил $576^{\mathrm{X}}$, оптическая эффективность системы $\sim 0.767$. В качестве ВОК для модуля рассматривались фоконы пирамидальной и конической форм двух типов.

Концентраторы первого типа представляли собой усеченную четырехгранную равностороннюю полую пирамиду либо усеченный полый конус с внутренними зеркальными стенками. Четырехгранная полая пирамида была изготовлена из полированной алюминиевой фольги (толщина $0.5 \mathrm{~mm}$ ) с защитным интерференционным слоем, обеспечивающим зеркальное отражение до 95\% в широком интервале длин волн. Отражающий конус изготавливался двумя способами: 1 - точение в латуни с последующим покрытием внутренней полированной поверхности серебром; 2 - формование из полированной алюминиевой фольги.

Концентраторы второго типа имели аналогичную форму (пирамида или конус с плоскими верхним и нижним основаниями) и выполнялись из оптического стекла марки К8. Концентрирование излучения в таких ВОК происходило за счет преломления света на верхней плоской поверхности и полного внутреннего его отражения от боковых поверхностей элементов.

На рис. 1 представлены фотографии изготовленных вторичных оптических концентраторов.

При изготовлении преломляющих фоконов размеры были выбраны аналогичными размерам отражающих фоконов. Все используемые фоконы имели высоту $20 \mathrm{~mm}$. Угол наклона боковых граней у отражающих и преломляющих четырехгранных усеченных пирамид рав- нялся $17^{\circ}$, диагональ выходного отверстия и нижнего основания усеченных пирамид составляла $1.65 \mathrm{~mm}$. Угол наклона образующей боковых поверхностей у отражающих и преломляющих фоконов круглой формы был выбран равным $22^{\circ}$, диаметр выходного отверстия и нижнего основания усеченных конусов $-1.6 \mathrm{~mm}$.

\section{2. Методика измерений}

Измерения вольт-амперных характеристик (ВАХ) экспериментальных модулей производились на имитаторе солнечного излучения, обеспечивающего в период вспышки ксеноновой импульсной лампы световой поток с плотностью $1000 \mathrm{~W} / \mathrm{cm}^{2}$ (спектром AM1.5D) и угловой расходимостью, идентичной расходимости светового потока, идущему от солнечного диска. Система позиционирования модуля в световом потоке обеспечивала прецизионные перемещения каждого из элементов исследуемых концентрирующих систем в трех координатах и поворот всей установленной конструкции относительно оптической оси падающего излучения. Блок измерений обеспечивал запись ВАХ ФЭП в период одиночного светового импульса. На рис. 2 приведены оптическая схема и фотография измерительной части установки с закрепленными ЛФ, ФЭП и установленным фоконом.

ЛФ и ФЭП с установленным фоконом закреплялись на держателях так, чтобы световой поток фокусировался на фотоприемной площадке ФЭП (т.е. в начальном положении ФЭП находится точно на оптической оси ЛФ и на фокальном расстоянии от нее). Для каждой установленной конфигурации модуля производилась запись нагрузочной ВАХ ФЭП. Рассматривались варианты линейного перемещения ФЭП с фоконом в фокальной плоскости (перпендикулярна оптической оси ЛФ) либо поворота (угловое дискретное перемещение) модуля со
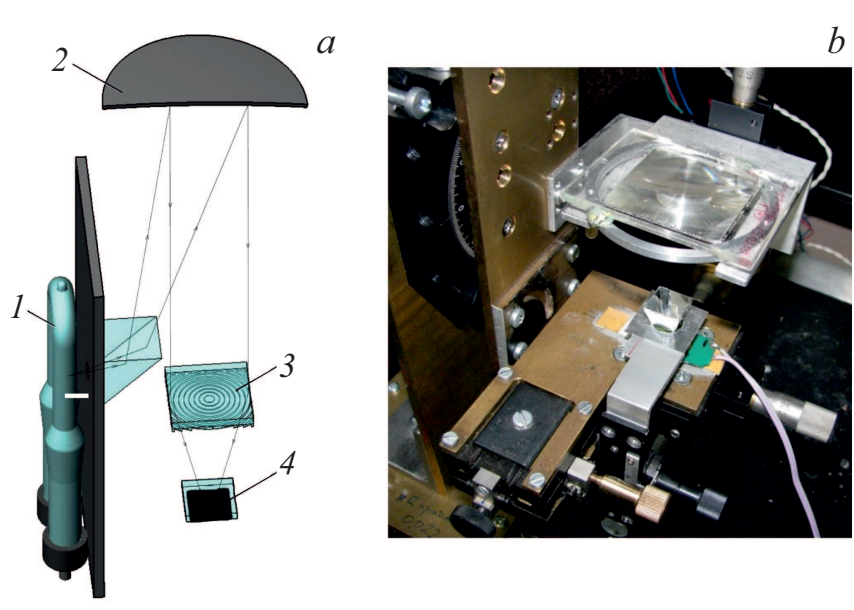

Рис. 2. Имитатор солнечного излучения: $a-$ оптическая схема имитатора солнечного излучения: $1-$ импульсная ксеноновая лампа-вспышка; 2 - сферическое зеркало; 3 - ЛФ; 4 - фотоэлектрический преобразователь. $b-$ фотография измерительной части установки с закрепленными ЛФ, ФЭП и установленным фоконом. 
сьюстированными элементами относительно „направления на Солнце“ (вокруг горизонтальной оси). Шаги линейных перемещений и углы поворотов задавались с помощью компьютерной программы и производились в интервалах между импульсами ксеноновой лампывспышки. По значениям тока короткого замыкания $\left(I_{s c}\right)$ ФЭП проводилась оценка уровня освещенности его фотоприемной площадки при каждом взаимном положении элементов разных концентрирующих систем или при угловой разориентации модуля. Сопоставление значений $I_{s c}$ одного и того же ФЭП, измеренных при фокусировке излучения парой ЛФ-ВОК и в режиме его прямой (без концентрирующей оптики) засветки световым потоком от имитатора, дает возможность рассчитать среднюю кратность концентрирования излучения на фотоприемной площадке ФЭП для выбранного варианта концентрирующей системы. Допустимый диапазон углов разориентации оценивался по уровню 0.9 от измеренных значений при нормальном падении лучей на первичную линзу $\left( \pm \Omega_{0.9}\right)$.

\section{3. Влияние параметров вторичных концентраторов на характеристики модуля}

При проведении экспериментов были исследованы характеристики концентраторных модулей с вторичными концентраторами в виде фоконов как отражающего, так и преломляющего типов разной конфигурации, выполненных в виде перевернутых усеченных пирамид, либо усеченных конусов. Для всех рассматриваемых вариантов ВОК обеспечивали повышение средней концентрации излучения на поверхности малоразмерных ФЭП за счет улучшения собирания излучения. Запись разориентационных кривых производилась при повороте (отклонении) концентраторного модуля относительно оптической оси „коллиматор-ЛФ-ФЭП“. При этом фоконы пирамидального типа устанавливались на поверхности ФЭП таким образом, чтобы верхние грани их входной апертуры были параллельны сторонам первичной ЛФ.

На рис. 3 представлены зависимости изменения средней концентрации излучения на фотоприемной поверхности ФЭП от угла разориентации концентраторного модуля с фоконами в виде перевернутых усеченных пирамид двух типов (отражающих и преломляющих).

Полученные разориентационные кривые сравнивались с характеристиками модуля без ВОК. Во всех случаях применение ВОК дает сушественное расширение разориентационных кривых. Угол допустимой (по уровню снижения средней концентрации 0.9) разориентации последовательно увеличивается с $\pm 0.3^{\circ}$ (модуль без ВОК) до $\pm 0.55^{\circ}$ и $\pm 0.75^{\circ}$ для модулей с отражающим и преломляющим фоконами соответственно. Сопоставление абсолютных значений средней концентрации излучения и хода разориентационных кривых для разных видов

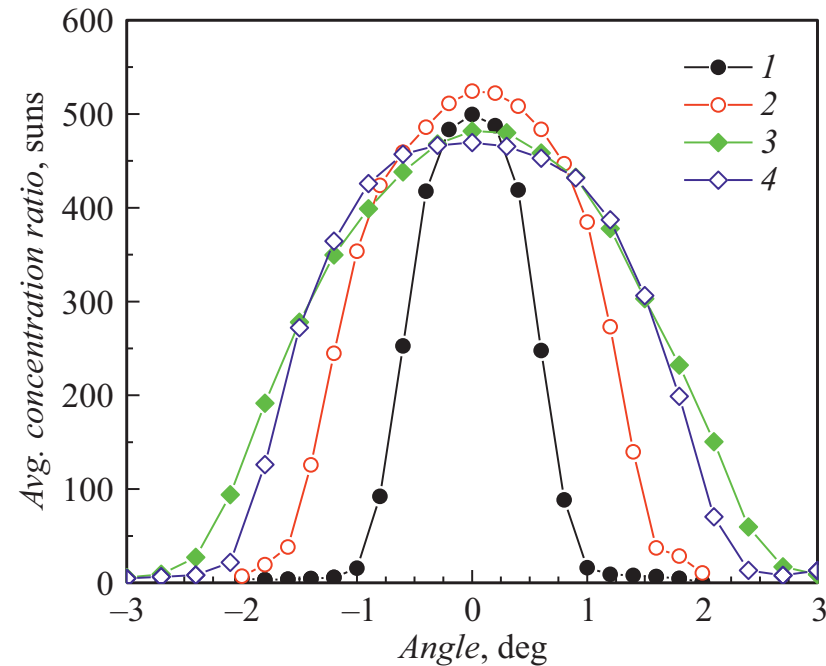

Рис. 3. Разориентационные кривые концентраторного модуля с ВОК пирамидальной формы: 1 - фотоприемник без вторичной оптики; 2 - фотоприемник с фоконом отражающего типа из алюминиевой фольги; $3,4-$ фотоприемник с фоконами преломляющего типа из оптического стекла.

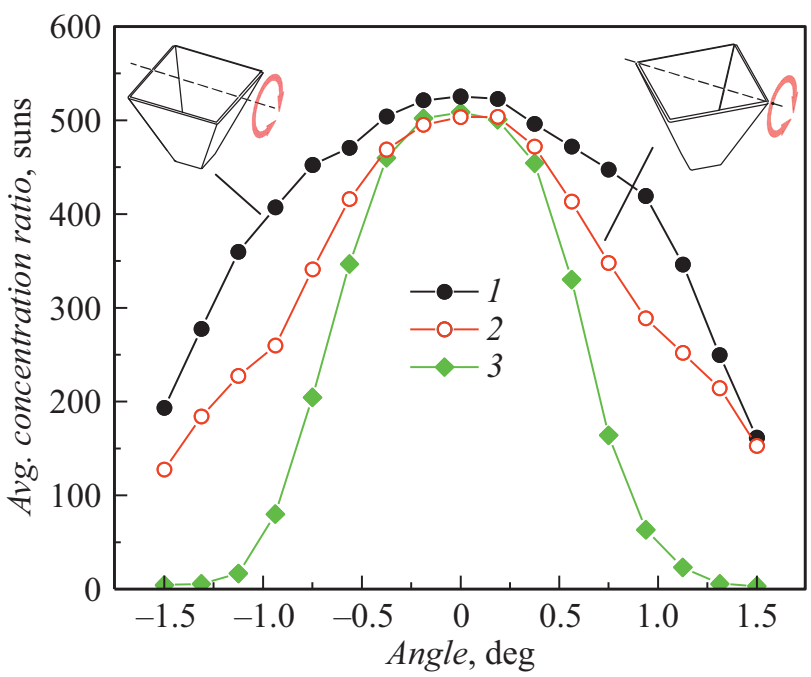

Рис. 4. Разориентационные кривые для концентраторного модуля с отражающим фоконом пирамидальной формы, записанные при установке фокона так, что две верхние кромки входной апертуры пирамиды фокона параллельны оси углового перемещения модуля (кривая 1); диагональ входной апертуры пирамиды параллельна оси углового перемещения модуля (кривая 2); и без вторичного концентратора (кривая 3 ).

ВОК пирамидального типа (рис. 3) позволяет отметить, что вторичный концентратор отражающего типа (кривая 2) в пределах углов до $\pm 0.75^{\circ}$ дает дополнительный энергетический выигрыш за счет высокой оптической эффективности отражающих поверхностей и собирания рассеянного излучения.

Рис. 4 демонстрирует изменение разориентационных характеристик концентраторного модуля с отражающим 


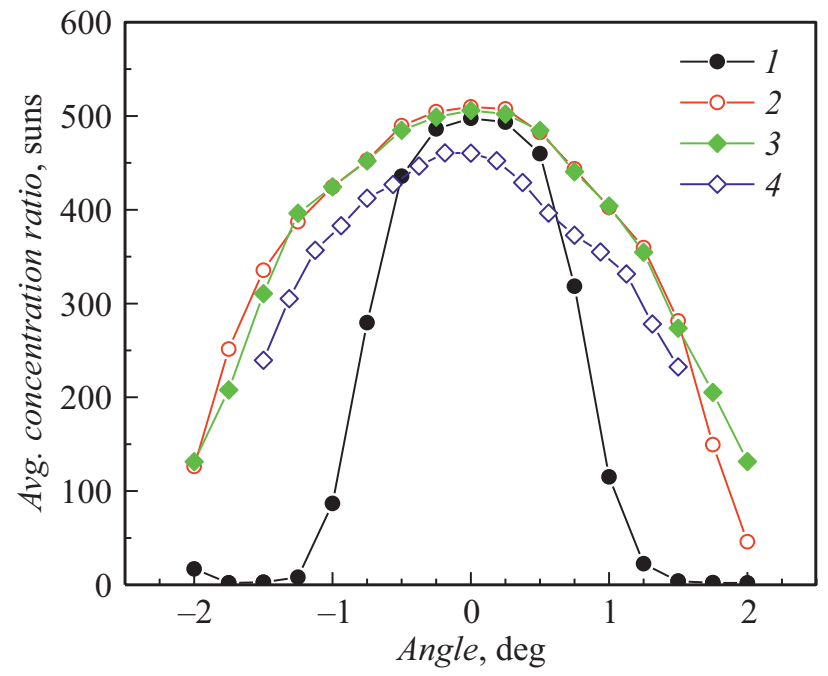

Рис. 5. Разориентационные кривые концентраторного модуля с ВОК конусообразной формы: 1 - фотоприемник без вторичной оптики; 2 - на фотоприемнике установлен отражающий фокон с покрытием из серебра; 3 - на фотоприемнике установлен отражающий фокон из полированной алюминиевой фольги; 4 - фотоприемник с преломляющим фоконом из оптического стекла.

фоконом пирамидальной формы для разных положений модуля относительно направления оси, вокруг которой производился поворот модуля относительно оптической оси коллиматора. При записи разориентационных кривых, представленных на рис. 4, модуль устанавливался относительно оси поворота в двух положениях: $1-$ чтобы две верхние кромки входной апертуры пирамиды фокона были параллельны оси поворота модуля (кривая 1); 2 - чтобы диагональ входной апертуры пирамиды была параллельна оси поворота модуля (кривая 2). Для сравнения на рисунке показана соответствующая зависимость для модуля без вторичного концентратора.

Как видно из хода кривых на рис. 4, наблюдается большее уширение разориентационной кривой при установке модуля в положение, когда верхние кромки входной апертуры пирамиды фокона были параллельны оси поворота модуля. Это обусловлено вкладом значительного количества лучей, идущих от первичного концентратора под большими углами. Этот эффект был учтен при конструировании отражающих конусов круглой геометрии, угол, образующий боковых стенок, был выбран равным $22^{\circ}$.

В случае использования ФЭП с круглой формой фотоприемной площадки более логично применение фоконов в форме перевернутого усеченного конуса. На рис. 5 представлены кривые изменения средней концентрации излучения на фотоприемной поверхности ФЭП от угла отклонения оптической оси модулей от оптической оси коллиматора при использовании в модулях фоконов преломляющего и отражающего типа в виде перевернутых усеченных конусов. Следует отметить, что выходные отверстия конусов равны по размеру фотоприемной площадке ФЭП. В варианте с преломляющим конусом из оптического стекла его установка на фотоприемную поверхность осуществлялись с помощью приклейки оптическим силиконом, который в этом случае выполнял функции просветляющей среды. Установка таких ВОК без приклеивания силиконом значительно усложняла монтаж фоконов в КФЭМ. Кроме того, в этом случае наблюдались значительные оптические потери из-за отражения света от нижнего основания конуса.

Отражающие металлические конусообразные фоконы как с покрытой серебром внутренней частью, так и выполненные из полированной алюминиевой фольги показали улучшенные разориентационные характеристики, аналогично пирамидальным фоконам из алюминиевой фольги. Допустимый угол разориентации, определяемый по разориентационной кривой на уровне 0.9 от максимума, для модуля с вторичной оптикой (преломляющего и отражающего типа) конусообразной формы составил $\pm 0.7^{\circ}$.

При нормальном падении излучения линейное перемещение ФЭП с фоконом в фокальной плоскости ЛФ позволяет производить запись кривой изменения концентрирования излучения от величины смещения фотоприемника относительно центрального положения. На рис. 6 приведены кривые изменения средней концентрации излучения на фотоприемной поверхности ФЭП в модулях с пирамидальными ВОК разных типов от величины смещения фотоприемника с установленным на нем вторичным концентратором. Наибольшее уширение кривой средней концентрации наблюдается при использовании в качестве ВОК пирамидального фокона из

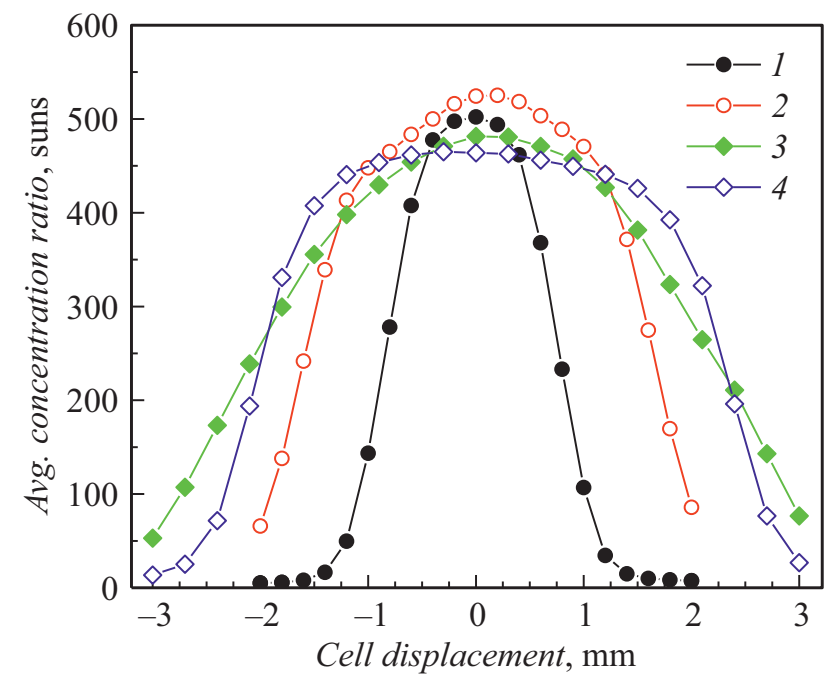

Рис. 6. Зависимости эффективности преобразования излучения концентраторными модулями с фоконами пирамидальной формы от сдвига фотоприемника относительно центрального положения при нормальном падении излучения: $1-$ фотоприемник без вторичной оптики; 2 - фотоприемник с отражающим фоконом из алюминиевой фольги; $3,4-$ фотоприемник с преломляющими фоконами из оптического стекла. 
оптического стекла. В этом случае, как следует из рис. 6 (кривая 4), возможно смещение центра фотоприемника с фоконом относительно оптической оси ЛФ на $\pm 1 \mathrm{~mm}$ при сохранении эффективности преобразования излучения на уровне 0.9 от максимального значения против $\pm 0.4 \mathrm{~mm}$ в модулях без фоконов.

\section{Заключение}

Исходя из приведенных результатов, можно заключить, что установка вторичного концентрирующего элемента в модуль с первичным концентратором в виде ЛФ размером $40 \times 40 \mathrm{~mm}$ дает возможность значительно увеличить допустимый угол разориентации до $\pm 0.75^{\circ}$ при сохранении 90\% от максимума выходной мощности КФЭМ. Кроме того, при сохранении таких же требований к эффективности и выходной мощности, в КФЭМ появляется возможность отклонения положения центра фотоприемника с установленным фоконом относительно оптической оси ЛФ до $\pm 1 \mathrm{~mm}$.

Использование в модулях вторичных оптических концентраторов преломляющего либо отражающего типа зависит от ряда факторов. Полые пирамидальные фоконы из алюминиевой фольги привлекательны с точки зрения более высокой эффективности фокусировки излучения при нормальной ориентации модуля, а также благодаря низкой стоимости производства. Недостатки этой конструкции состоят в сложностях монтажа пирамидальных фоконов на поверхностях фотопреобразователей и в риске электрохимической коррозии в месте контакта ФЭП и фокона. Преломляющие (стеклянные) фоконы пирамидального типа обеспечивают больший допустимый угол разориентации концентраторных модулей. Однако в концентраторных системах с фоконами такого типа наблюдаются несколько меньшие значения эффективности фокусировки излучения при точной ориентации модулей на Солнце. Следует отметить, что массовое производство стеклянных вторичных оптических элементов намного более длительное и дорогостоящее, чем производство алюминиевых элементов. Тем не менее в случае достаточно небольших размеров фотоприемников $(1-2 \mathrm{~mm})$ использование стеклянных преломляющих оптических элементов достаточно перспективно за счет лучших разориентационных характеристик.

\section{Благодарности}

Авторы благодарят В.М. Андреева за участие и обсуждение полученных результатов и А.В. Чекалина за помощь при оформлении работы.

\section{Финансирование работы}

Исследование выполнено за счет гранта Российского научного фонда (проект № 17-79-30035).

\section{Конфликт интересов}

Авторы заявляют, что у них нет конфликта интересов.

\section{Список литературы}

[1] M.A. Green, E.D. Dunlop, J. Hohl-Ebinger, M. Yoshita, N. Kopidakis, A.W.Y. Ho-Baillie. Prog Photov: Res Appl., 28, 3 (2019). https://doi.org/10.1002/pip.3228

[2] Е.В. Бобкова, В.А. Грилихес, А.А. Солуянов, М.З. Шварц. Письма в ЖТФ, $32(23), 86$ (2006). [E.V. Bobkova, V.A. Grilikhes, A.A. Soluyanov, M.Z. Shvarts. Tech. Phys. Lett., 32 (12), 1039 (2006).

DOI: https://doi.org/10.1134/S1063785006120133]

[3] C. Domınguez, I. Anton, G. Sala, S. Askins. Prog. Photovoltaics, 21 (7), 1478 (2013). DOI: https://doi.org/10.1002/pip.2227

[4] R. Herrero, M. Victoria, C. Dominguez, S. Askins, I. Anton, G. Sala. AIP Conf. Proc., 1679, 050006 (2015). DOI: http://dx.doi.org/10.1063/1.4931527

[5] V.M. Andreev, V.A. Grilikhes, A.A. Soluyanov, E.V. Vlasova, M.Z. Shvarts. 23rd European Photovoltaic Solar Energy Conference. 2008. P. 126. DOI: https://doi.org/10.4229/23rdEUPVSEC2008-1BO.5.1

[6] P. Benitez, J.C. Minano, P. Zamora, R. Mohedano, A. Cvetkovic, M. Buljan, J. Chaves, M. Hernandez. Opt. Express., 18 (S1), A25 (2010). DOI: https://doi.org/10.1364/OE.18.000A25

[7] M. Victoria, C. Dominguez, I. Anton, G. Sala. Opt. Express, 2009, 17 (8), 6487 (2009). DOI: https://doi.org/10.1364/OE.17.006487

[8] K. Shanks, S. Senthilarasu, T.K. Mallick. Renewable and Sustainable Energy Reviews. 60, 394 (2016). DOI: http://dx.doi.org/10.1016/j.rser.2016.01.089

[9] B.M. Coughenour, T. Stalcup, B. Wheelwright, A. Geary, K. Hammer, R. Angel. Optics Express, 22 (S2), A211 (2014). DOI: https://doi.org/10.1364/oe.22.00a211

[10] M. Wiesenfarth, I. Anton, A.W. Bett. Appl. Phys. Rev., 5, 041601 (2018). DOI: https://doi.org/10.1063/1.5046752

[11] V.D. Rumyantsev, V.M. Andreev, A.W. Bett, F. Dimroth, M. Hein, G. Lange, M.Z. Shvarts, O.V. Sulima. Progress in development of all-glass terrestrial concentrator modules based on composite Fresnel lenses and III-V solar cells, Proc. of the 28th IEEE PVSC, (Alaska, September, 2000) p. 1169. 